Belhenniche Samir. E

Aounallah Mohammed

Imine Omar

Çelik Fahri

http://dx.doi.org/10.21278/brod67403

ISSN 0007-215X

eISSN 1845-5859

\title{
EFFECT OF GEOMETRIC CONFIGURATIONS ON HYDRODYNAMIC PERFORMANCE ASSESSMENT OF A MARINE PROPELLER
}

\author{
UDC 629.5(05):629.5.015.2:629.5.016.7:629.5.024.71
}

Original scientific paper

\begin{abstract}
Summary
The present paper deals with the effect of the geometric characteristics on the propeller hydrodynamic performances. Several propeller configurations are created by changing number of blades, expanded area and pitch ratios. The Reynolds-Averaged Navier-Stokes (RANS) equations are solved using the commercial code FLUENT 6.3.26. The standard $k-\varepsilon$ and the $k-\omega S S T$ models are used for the steady uniform and the transient non-uniform ship wake. Overlapping propellers arise from high expanded area involve that the computational domain should be created with several multi-blocks. Thrust, torque and efficiency coefficients of the generated propellers are compared with available experimental data. The computational results reveal that both standard $k-\varepsilon$ and $k-\omega S S T$ models guarantee acceptable level of accuracy in open water condition and unsteady flow predictions. This parametric study has also allowed achieving optimal shape factors ensuring best hydrodynamic performances.
\end{abstract}

Key words: $\quad$ Marine propeller; open water; blade; expanded area; geometric pitch; hydrodynamic performances;

\section{Introduction}

The prediction of the flow around marine propellers enjoys noticeable interest from the hydrodynamic sciences communities and become one of the challenges of CFD. The complex geometry of marine propellers, grid generation and turbulence modelling remain the significant problems opposed the numerical simulations. The conventional Seiun Maru (CP) and the highly skewed (HSP) marine propellers are widely used as a benchmark and known for their abundant experimental data. T. Watanabe et al. [1] carried out numerical simulations for steady and unsteady non-cavitating conditions with $k-\omega$ and $k-\omega S S T$ respectively. The predicted values of torque and thrust coefficients were found in good agreement with the experimental results. Bin Ji et al. [2] investigated the unsteady cavitating flow around the HSP Seiun Maru propeller using the $k-\omega S S T$ model; they established a periodic development of cavity on the blade tip due to the gravity effect and the non-uniform ship 
wake. It is also observed a larger pressure fluctuation close to the propeller surface during its revolution. T. Kanemaru et al. [3] presented a computational method based on the simple surface panel method "SQCM" which satisfies the Kutta condition for steady and unsteady cavitating propeller problems. Using the CP and HSP Seiun Maru propellers the numerical tests were performed to predict thrust and torque for a wide range of advance coefficient and cavitation numbers. The authors reported that the current method can express faithfully the area and the volume of the cavity variations. Bin Ji et al. [4] used the $k-\omega S S T$ turbulence model to predict the characteristics of the unsteady cavitation and the alleviation of pressure fluctuations around the CP and HSP Seiun Maru propellers with different skew angles. The results showed a relationship between the skew angle and the cavitation characteristics. The pressure fluctuation amplitudes of the HSP are found 50 70\% less than that for the CP and consequently a net decrease of noise and vibration levels are reported for the HSP propeller.

Recently, in order to reduce fuel consumption and air pollution, several studies were devoted to marine propeller geometric effects such as skew and rake angles on hydrodynamic performances. Ghassemi [5] used the potential Boundary Element Method (BEM) to study the influence of the ship wake and the skew on the CP and HSP Seiun Maru propellers performances. The employed method demonstrates that for a lower skew, the total thrust and torque for CP give larger fluctuations than HSP. However, this latter reduces the propeller-excited vibration on the entire hull. Krasilnikov et al. [6] studied the effect of the skew angle on the propeller characteristics, three propellers were considered with several skew angles; (0, 31 and $62 \mathrm{deg}$.), the $k-\omega S S T$ model was selected for the turbulence closure which is widely used for swirling and blade row machinery applications. It was concluded that the increasing of the skew angle leads to a relative decrease of torque at heavier loadings, and reciprocally. Mossad et al. [7] performed an analysis of the skew effect on cavitation inception and propeller vibrations. The results advise that a rise of skew produces larger cavitation volume on the propeller blade. It is suggested that the skew range between 45-60 degrees allows enhanced hydrodynamic performances and reduced vibrations. Hayati [8] explored the influence of the rake angle on the propeller hydrodynamic performances. It was revealed that the linear rake distribution is insignificant for conventional propellers. At high propeller loads, the propeller thrust is improved but the required torque must increases too. Ghassabzadeh et al. [9] studied the skew angle effect on the hydrodynamic performances for composite propellers compared with copper high tensile brass propeller. Several skew angles were tested $(0,25,50,55 \mathrm{deg}$.) for a wide range of advance coefficient, i.e., $0.2<J<0.9$. The survey reveals that the maximum deflection of blade increases as the skew angle increases and the efficiency gets its optimum for heavier loads. I. Yasuhiko [10] explored the hydrodynamic characteristics of a marine propeller with a raked tip in order to improve its efficiency. It was observed a reduction of the negative pressure area on the blade which improves noticeably hydrodynamic performances once the tip is curved in the pressure side direction.

Basically, a marine propeller design is carried out using the results of the open-water tests on a series of model propellers and finding suitable laws that govern the propeller shape such as chord length, pitch ratio, thickness, skew and rake angles and as well as the section profile. After the selection of the criteria design which acts as a boundary condition, the propeller design can be initiated by setting some key parameters such as thrust, ship wake distribution and rotational speed. The other features can be determined from cavitation and vibration considerations to get efficient device. The present paper is devoted to the numerical investigation propeller performances that assists the designer to select the adequate solution in the case of propeller project. It is obvious that the founded solution is affected by the propeller design initial data. In the first part, the presented computation method is validated for the 
conventional Seiun Maru in steady and transient non-uniform ship wake. Next, fourteen new configurations are shaped from the initial CP Seiun Maru propeller and tested numerically in open water conditions. The main objective of this part is to evaluate the effect of blade number, expanded area and geometric pitch ratios on the hydrodynamic performances. The obtained results are compared with similar Wageningen propellers.

\section{Propeller geometric characteristics}

The conventional Seiun Maru propeller is chosen as a reference case. It is a Japanese AU serie with a modified NACA 66 section and has taken the name of the Seiun Maru ship. It contains 5 blades with a diameter of $D=3.6 \mathrm{~m}$. It has also a fixed pitch and an expanded area ratio of $A_{E} / A_{0}=0.65$.

To generate the geometry of the propeller, a FORTRAN program lists the geometric characteristics found in reference [1] and provides the spatial points coordinates for different cross sections. For each radius, the corresponding profile is moved by the skew in the $x$ direction and by the rake in the y direction to obtain the expanded section. Then, the obtained section is transformed to a developed one using trigonometric projections. Finally, the profile is deflected by its geometric pitch angle to obtain the projected section. The obtained points coordinates are then exported to the pre-processor GAMBIT, and are connected with spline lines. Surfaces are generated by connecting lines and then the volume of the blade is created. The shaft is connected to the propeller root blade using the T-junction technique. The 3D geometry of the CP Seiun Maru and the flow chart of the FORTRAN program are shown respectively in the figure 1 and 2 .

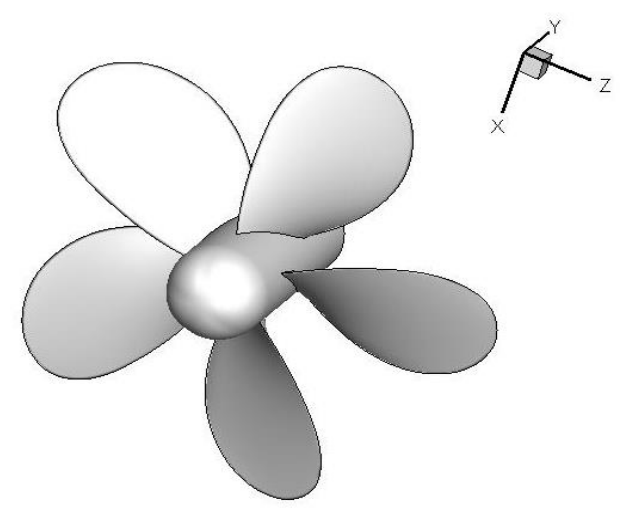

Fig. 1 Geometry of Seiun Maru CP propeller 
Belhenniche Samir. E, Aounallah Mohammed Imine Omar, Çelik Fahri
Effect of geometric configurations on hydrodynamic performance assessment of a marine propeller

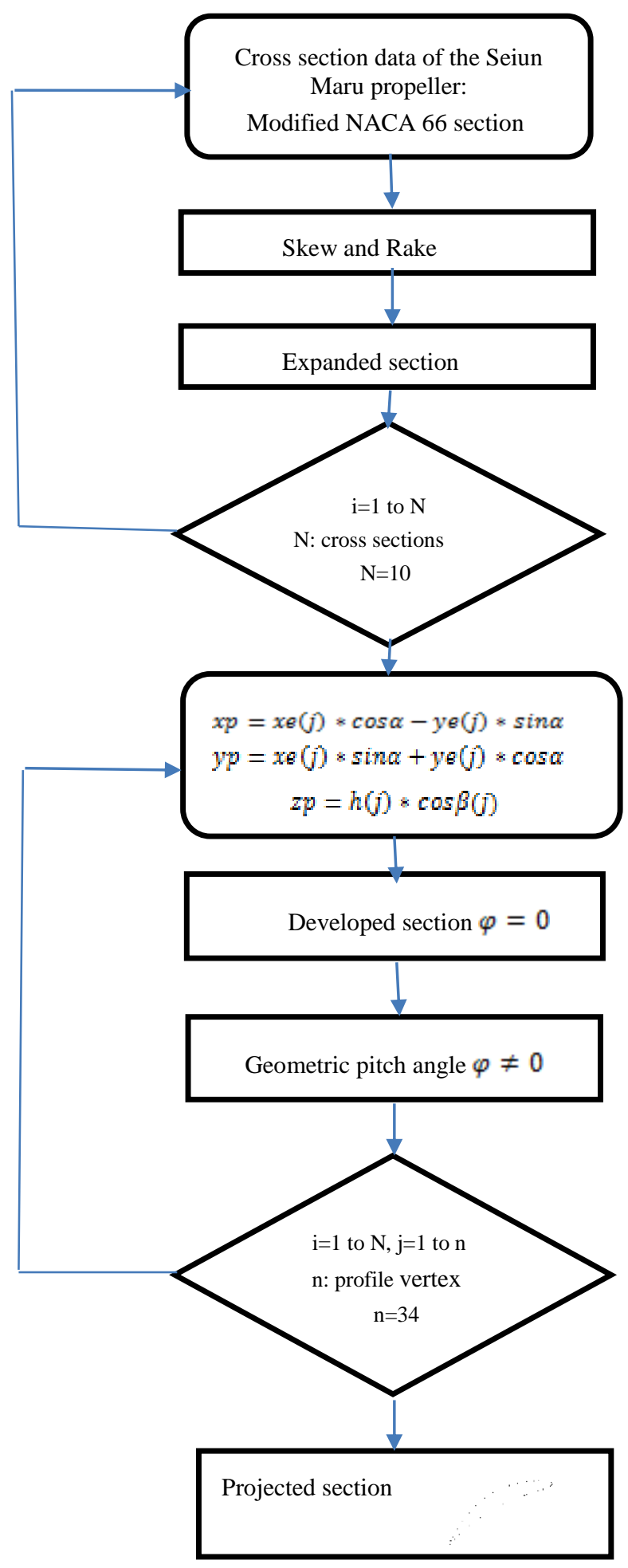

Fig.2 Flow chart 
Effect of geometric configurations on hydrodynamic performance assessment of a marine propeller
Belhenniche Samir. E, Aounallah Mohammed Imine Omar, Çelik Fahri

\section{Mathematical formulation and numerical procedure}

The 3D turbulent flow around the propeller is described by the Averaged Reynolds equations:

$$
\begin{aligned}
& \frac{\partial u_{i}}{\partial x_{i}}=0 \\
& \frac{\partial\left(\rho u_{i}\right)}{\partial t}+\frac{\partial\left(\rho u_{i} u_{j}\right)}{\partial x_{j}}=-\frac{\partial P}{\partial x}+\frac{\partial}{\partial x_{j}}\left(\mu \frac{\partial u_{i}}{\partial x_{j}}-\overline{\rho u_{i}^{\prime} u_{j}^{\prime}}\right)
\end{aligned}
$$

Where $u_{i}$ is the averaged velocity, $P$ is the averaged pressure, $\rho$ is the density, $\mu$ is the dynamic viscosity and $-\overline{\rho u_{z}^{\prime} u_{j}^{\prime}}$ is the Reynolds stress. The turbulence models of SpalartAllmaras [11], standard $k-\varepsilon$ of Launder [12], standard $k-\omega$ of Wilcox [13] and SST $k-\omega$ [14] of Menter are used and evaluated by comparing their results against the experimental data. Explicit details of all the models can be found easily in the literature.

In open water case, a steady simulation is carried out using the rotational periodic in order to reduce the mesh size and CPU time with $72^{\circ}$ in between. The computational domain is divided into six blocks with an inner one covering a single blade as shown in figure 3 . The inlet boundary is set at $1.5 \mathrm{D}$ with a uniform inflow depending on the advance coefficient $J$ The outlet is fixed at $3.5 \mathrm{D}$ with a static pressure condition and the outer boundary is at $1.4 \mathrm{D}$ from the shaft axis $[15,16]$. The slip condition is set for the top outer boundary while the adherence condition is imposed for the blade and hub surfaces. The fluid is considered rotational around the shaft axis by using the Moving Reference Frame (MRF) option.
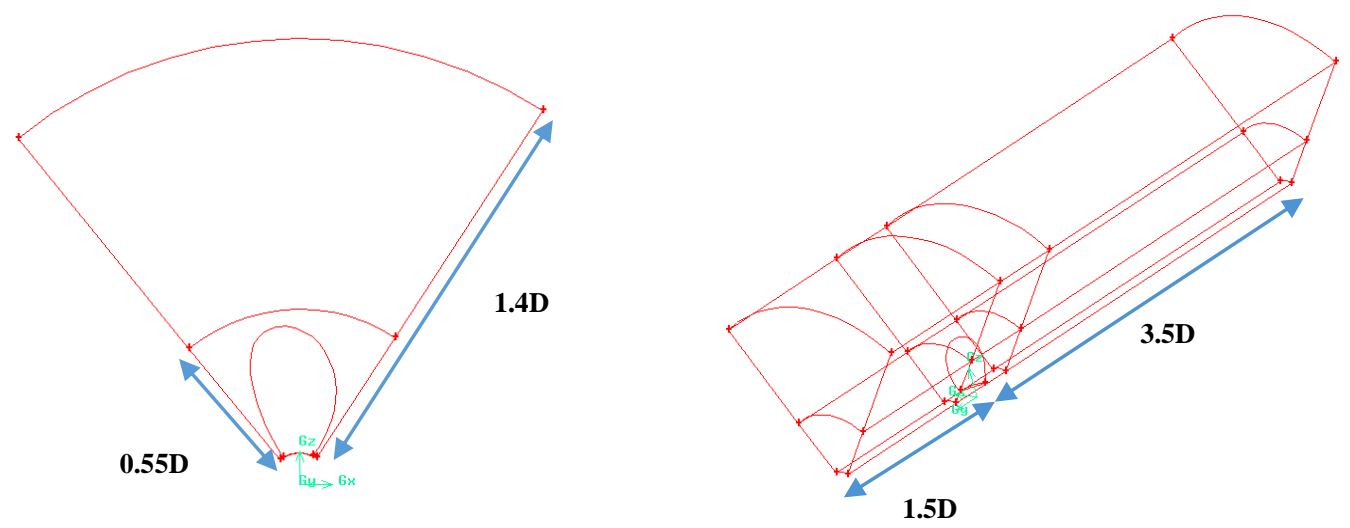

Fig.3 Computational domain for the steady case

For this case, an unstructured mesh is generated using GAMBIT pre-processor. First, the blade surface is meshed with $0.0055 D$ triangles cells size, as it is illustrated in figure 4 (a). A local hybrid grid is adopted with a constant successive ratio distribution. The inner domain is meshed with tetra cells ( $43 \%$ of the total elements number) while the hexahedral cells are used to mesh the remaining five blocks using an exponent distribution (figure 4 (b)). 
Belhenniche Samir. E, Aounallah Mohammed Imine Omar, Çelik Fahri
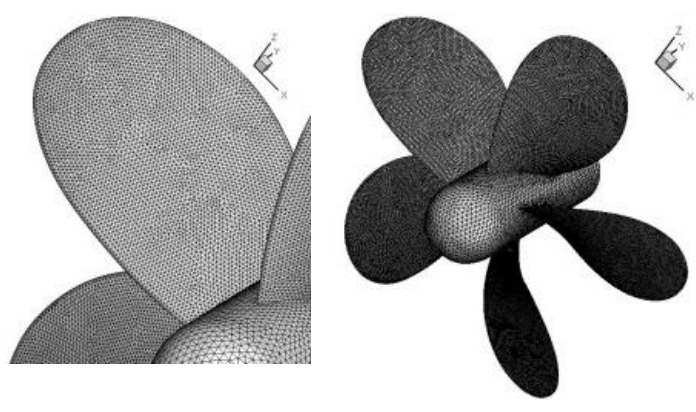

(a)
Effect of geometric configurations on hydrodynamic performance assessment of a marine propeller

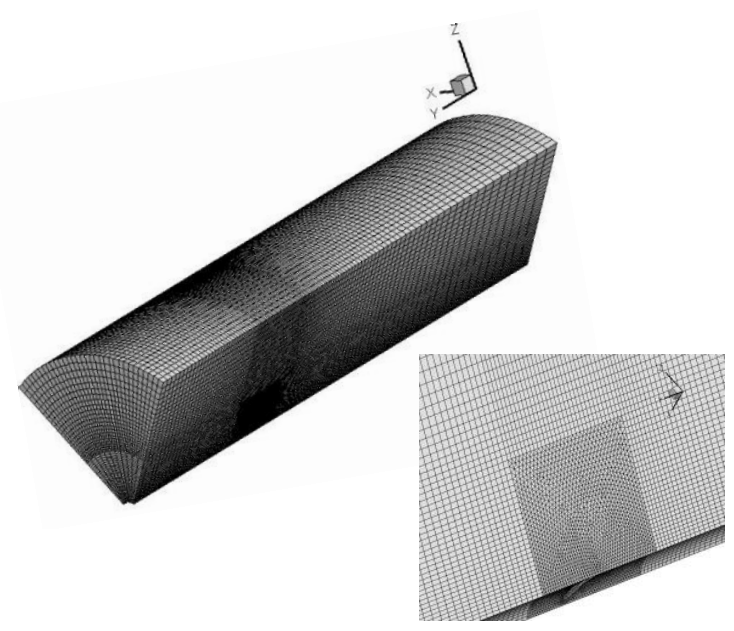

(b)

Fig.4 Grid generation

For the unsteady case, the entire five blades are considered to simulate the flow in nonuniform ship wake as shown in figure 5. The inlet, outlet and top boundaries are respectively located at $0.35 D, 6.7 D, 3 D$ from the center of the propeller. The computational domain is split into six cylinder blocks; four are stationary and the rest rotate with the propeller using the Sliding Mesh Technique [17]. A total of 1.8 million cells are generated with the same boundary conditions as the steady case excepting periodic conditions. Furthermore, at the inner rotating inlet, the axial components of the velocities $V_{a}$ are calculated from the measured nominal wake distribution as follow:

$$
V_{a}=V_{0}(1-w(r, \theta))
$$

With their appropriate coordinates:

$$
\begin{aligned}
& x(r, \theta)=r(i) \cdot \cos \left(\frac{\theta(i) \pi}{180}\right) \\
& z(r, \theta)=r(i) \cdot \sin \left(\frac{\theta(i) \pi}{180}\right)
\end{aligned}
$$
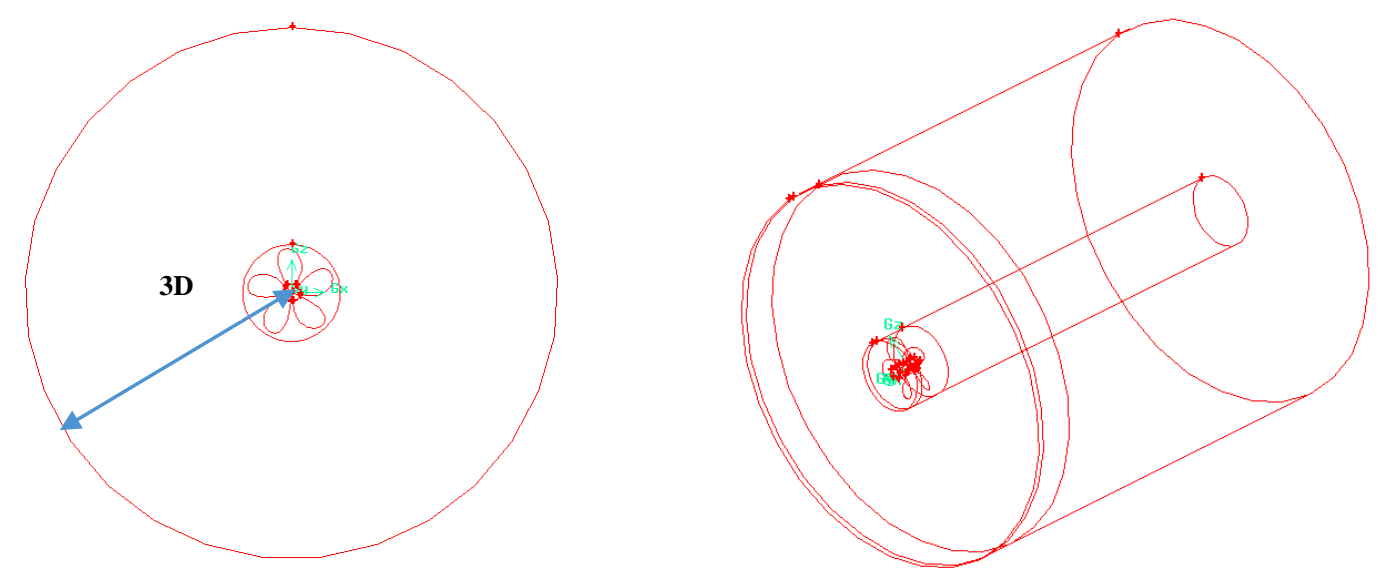

Fig.5 Computational domain for the unsteady case 
Effect of geometric configurations on hydrodynamic performance assessment of a marine propeller
Belhenniche Samir. E, Aounallah Mohammed Imine Omar, Çelik Fahri

The Reynolds equations are solved using FLUENT 6.3.26 code based on the finite volume method. For the steady and unsteady cases, the velocity-pressure coupling is respectively resolved with SIMPLE and PISO algorithms. QUICK scheme is adopted for the discretization the momentum equations while the standard scheme is chosen to discretize the continuity equation. Upwind first order scheme is selected to discretize the turbulent kinetic energy and dissipation rate equations. The relaxation factors have been adjusted for each simulation in order to accelerate convergence.

\section{Validation:}

\subsection{Open water characteristics}

The numerical simulations for the steady case are carried out on the Seiun Maru model with a scale of $1 / 9$ to match the conditions of the open water experiment done by Ukon [18, $19,20]$. For all numerical simulations, the propeller revolution is kept constant $n=217.8 \mathrm{rpm}$. Table 1 shows the estimated open water efficiency for the different turbulence models compared with the experiment. In overall, the standard $k-\varepsilon$ results give closest predictions to the experiment for a wide range of advance coefficient $J$. Indeed, the minimal average error is founded for this model which is evaluated to $6 \%$. For this reason, the standard $k-\varepsilon$ will be considered in the parametric study focused on the geometric characteristics effect due to its suitable accuracy.

Table 1 Open water efficiency with different turbulence models

\begin{tabular}{|c|c|c|c|c|c|}
\hline $\boldsymbol{I}$ & \multicolumn{1}{|l|}{ Exp. } & \multicolumn{1}{l|}{$\boldsymbol{S}-\boldsymbol{A}$} & $\boldsymbol{k}-\boldsymbol{\varepsilon}$ & $\boldsymbol{k}-\boldsymbol{\omega}$ SST \\
\hline 0.1 & 0,117 & 0.108 & 0.109 & 0.104 & 0,109 \\
\hline 0.2 & 0,227 & 0.217 & 0.217 & 0.207 & 0,217 \\
\hline 0.3 & 0,334 & 0.315 & 0.324 & 0.296 & 0,346 \\
\hline 0.4 & 0,438 & 0.410 & 0.420 & 0.402 & 0,422 \\
\hline 0.5 & 0,529 & 0.496 & 0.513 & 0.487 & 0,513 \\
\hline 0.6 & 0,605 & 0.561 & 0.593 & 0.566 & 0,593 \\
\hline 0.7 & 0,651 & 0.611 & 0.653 & 0.618 & 0,670 \\
\hline 0.8 & 0,652 & 0.630 & 0.686 & 0.639 & 0,686 \\
\hline 0.9 & 0.550 & 0.567 & 0.647 & 0.549 & 0,677 \\
\hline 1.0 & 0,260 & 0.121 & 0.304 & 0.110 & 0.302 \\
\hline Average error & - & $\mathbf{1 0 \%}$ & $\mathbf{6 \%}$ & $\mathbf{1 1 \%}$ & $\mathbf{7 \%}$ \\
\hline
\end{tabular}

Figure 6 shows the open water characteristics for different advance coefficient $J$ compared with the corresponding experimental values. In overall, the numerical results expressed by thrust, torque and efficiency are in good agreement with only some slightly discrepancies. 


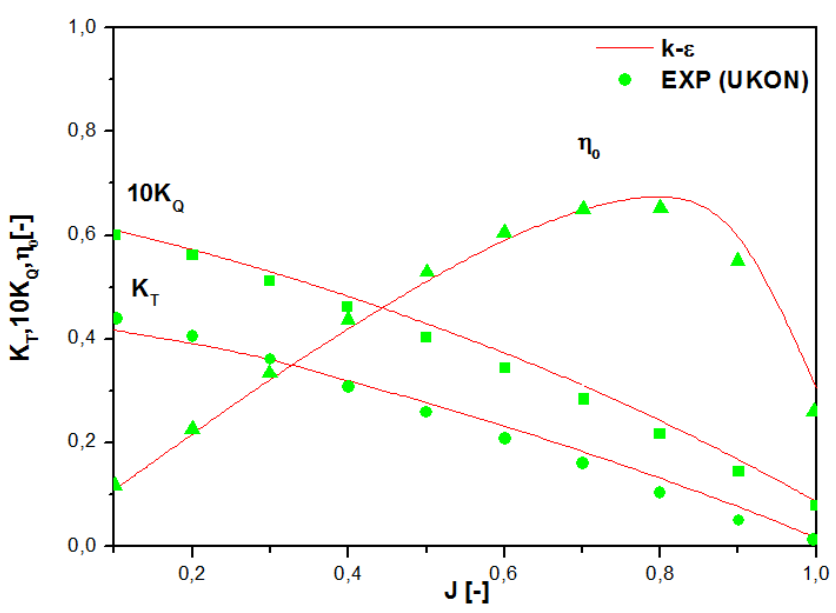

Fig.6 Open water characteristics

\subsection{Behind the ship hull}

The unsteady flow simulation with non-uniform ship wake is carried out for the full scale propeller. The operating conditions are set with propeller revolution $n=91.3 \mathrm{rpm}$ and ship speed $V_{0}=9.1$ knots corresponding to an advance coefficient of $J=0.855$. In this section, only $k-\varepsilon$ and $k-\omega S S T$ turbulent models are tested on a computer i7 2.4 GHZ 4GO RAM. The time step is set to $0.0018 \mathrm{~s}$ corresponding to the rotation angle of 1 degree [21]. Figure 7 shows the calculated thrust coefficient $K_{T}$ for one and five blades during one revolution compared with Nakatake et al. [22]. Qualitatively, the thrust prediction has the same trend as Nakatake calculation. Considering a single blade, both turbulence models give undistinguishable thrust coefficient while for the whole propeller the comparison shows that there is a very slight difference. In addition, it is noted that the load variation on the blade is highly related to the material resistance and fatigue predictions. In this case, the minimum and maximum values of $K_{T}$ are respectively 0.0278 and 0.0831 , giving an estimated variation nearby $66 \%$.

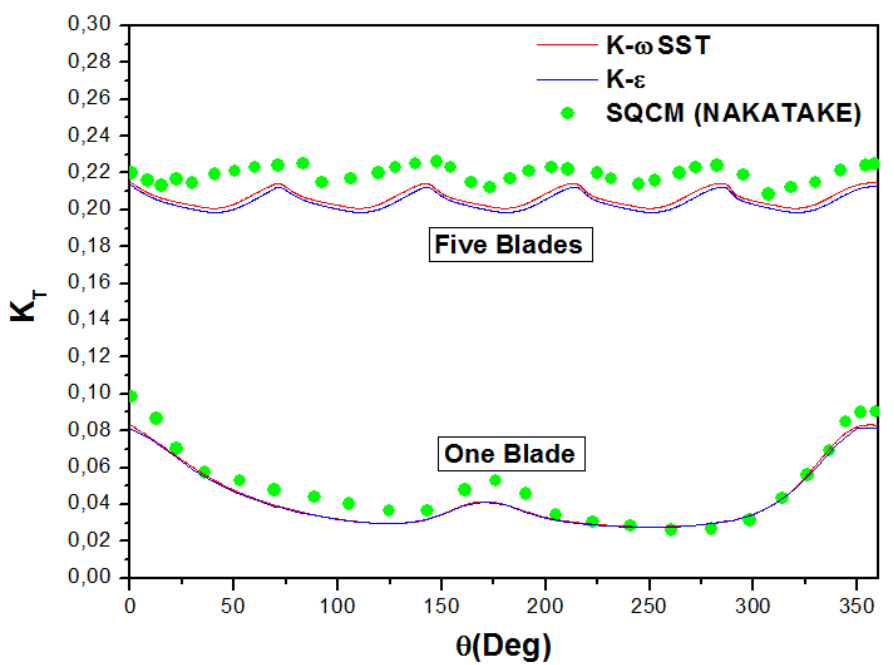

Fig.7 Variation of $K_{T}$ during propeller rotation 
Figure 8 shows the pressure coefficient on the blade suction for different angle positions. The angle of 0 degree corresponds to the top position. The present figure confirms the effect of the non-uniform inflow on the blade pressure distributions. At the top position where the axial flow velocity reaches its minimum value, the peak of the negative pressure on the backside is largest which leads to the occurrence of cavitation.
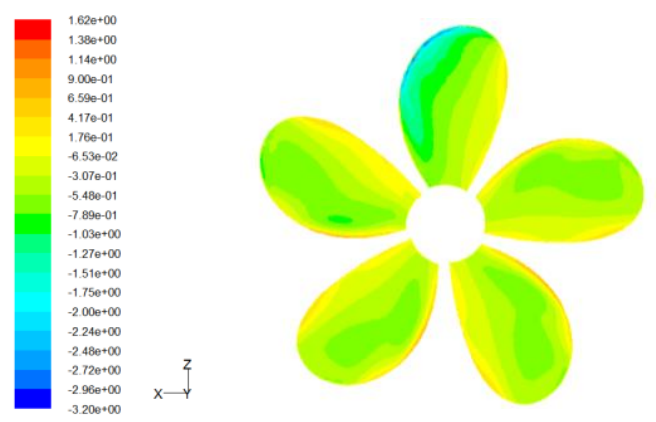

(a) $0^{\circ}$
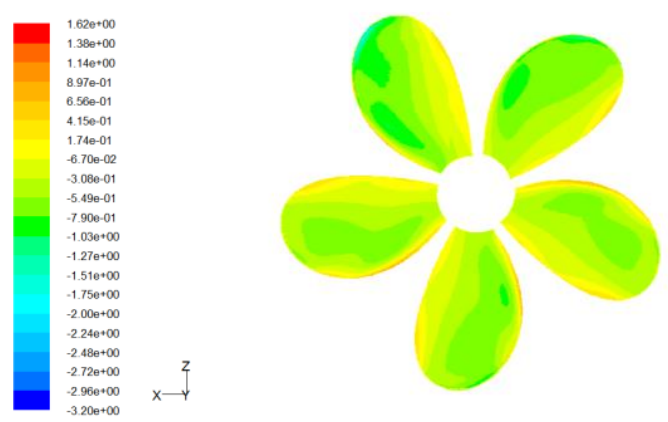

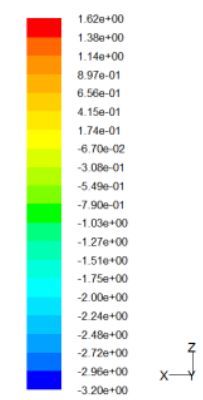

(c) $180^{\circ}$ (b) $90^{\circ}$
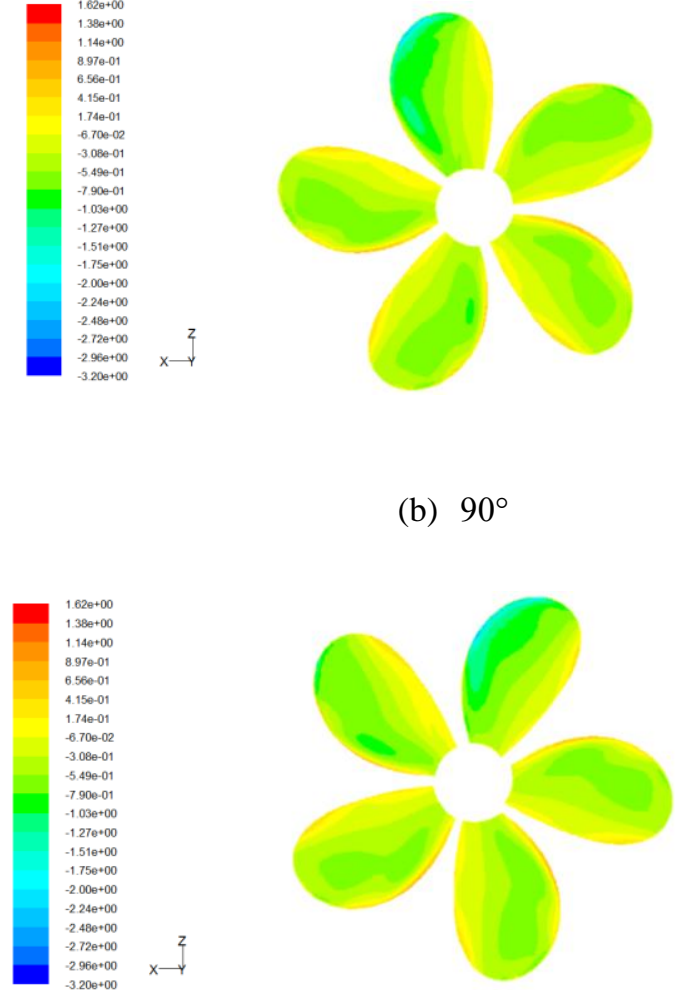

(d) $270^{\circ}$

Fig.8 Pressure coefficient distribution for CP Seiun Maru propeller

\section{Results:}

To examine the effect of geometric characteristics, a series of marine propellers are generated by changing blade numbers, expanded area and geometric pitch ratios using the FORTRAN program. All the subsequent simulations will be done in uniform open water flow condition and using the standard $k-\varepsilon$ model. The same mesh method and boundary conditions are set for uniform flow with periodic conditions respectively.

\subsection{Blade number $Z$ :}

Three new propellers with different blade number $(Z=4,6,7)$ are created by keeping the same expanded area ratio, $A_{E} / A_{0}=0.65$, and the similar pitch ratio, $P / D=0.95$, (figure 9 ). 
The new chord lengths, $C^{*}$, are proportional to the reference chord using the following formula:

$$
\frac{A_{e}}{A_{0}}=Z \frac{\int_{r_{h}}^{R} C d r}{\pi\left(R^{2}-r_{h}^{2}\right)}=Z^{*} \frac{\int_{r_{h}}^{R} C^{*} d r}{\pi\left(R^{2}-r_{h}^{2}\right)}
$$

Where $r_{h}$ is the hub radius.

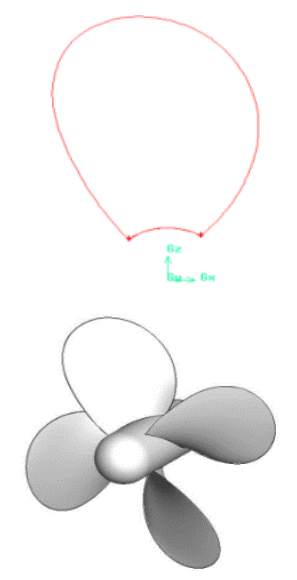

$\mathrm{Z}=4$

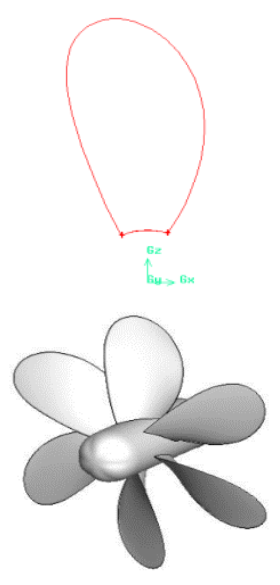

$\mathrm{Z}=6$

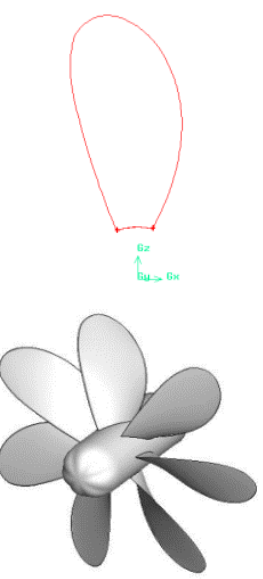

$\mathrm{Z}=7$

Fig. 9 Blade shape and propeller geometries

Figure 10 shows the calculated open water characteristics of the tested propellers compared to those of NSMB propellers. It is important to note that the compared propellers have identical blade number, expanded area ratio and pitch distribution. Good qualitative agreement is revealed particularly for the four bladed propeller. The observed discrepancies are mainly due to the difference between the other geometric features for the compared propeller pairs.
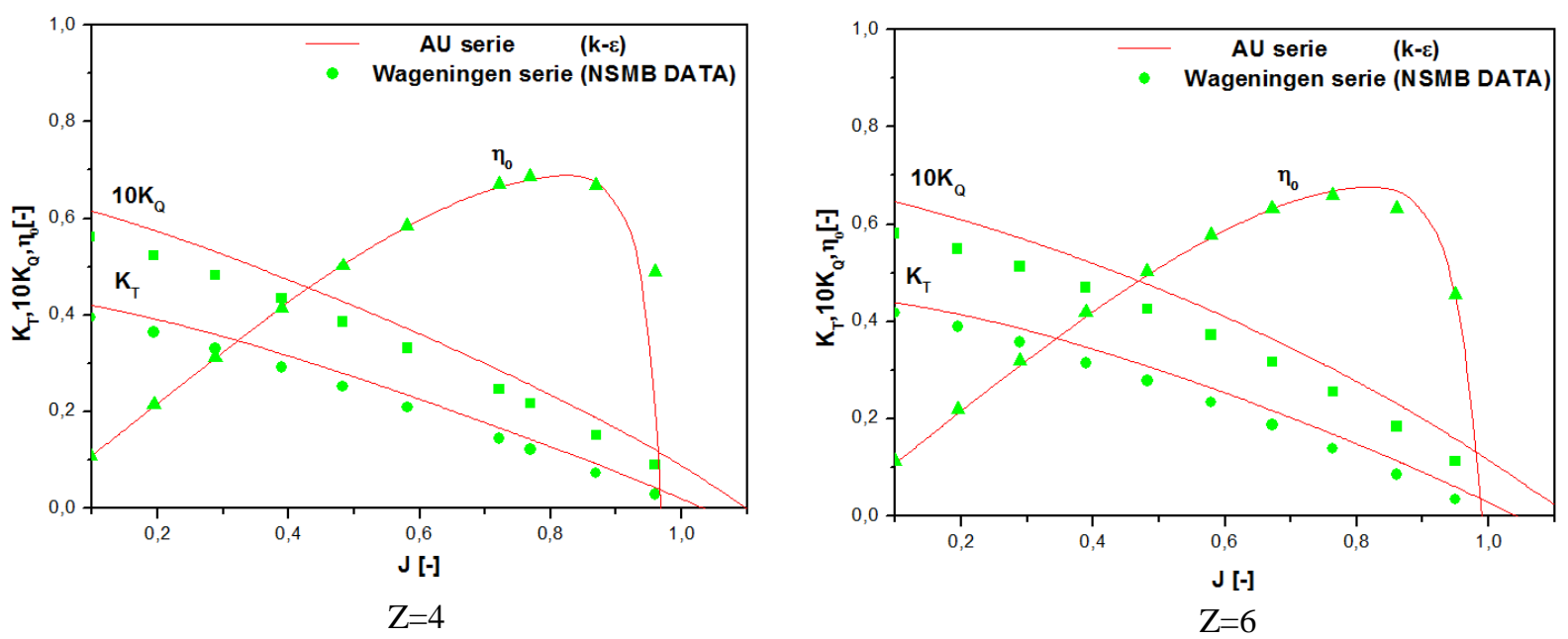


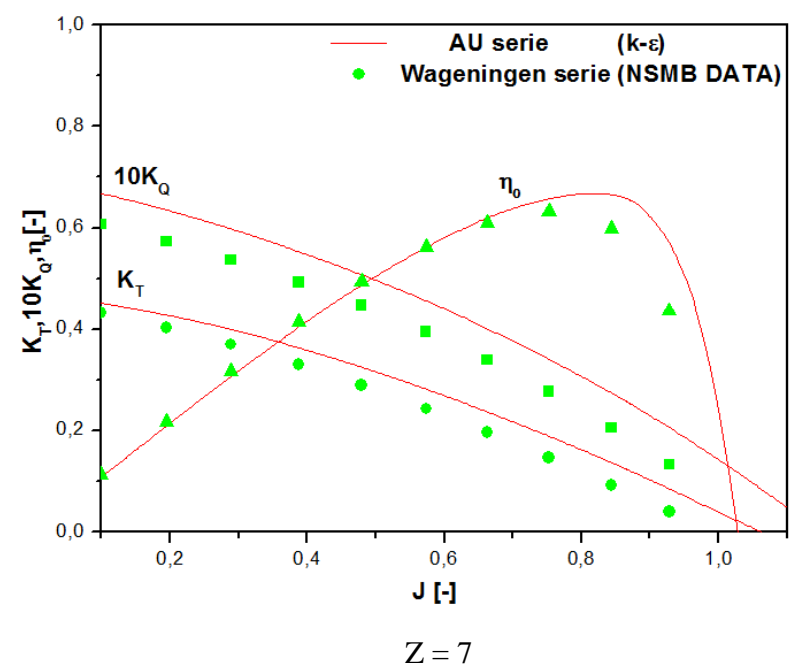

Fig. 10 Open water characteristics for $Z=4,6$ and 7 blades

Table 2 exposes the results of the tested propellers for the advance coefficient $J=0.7$ which corresponds to the propeller optimum. It clearly appears that the four bladed propeller gives the higher efficiency $\eta_{0}=66 \%$ among the other configurations and particularly with an increase of $0.7 \%$ in comparison to the initial Seiun Maru propeller [23].

Table 2 Open water characteristics

\begin{tabular}{|c|r|r|r|}
\hline $\boldsymbol{Z}$ & \multicolumn{1}{|c|}{$\boldsymbol{K}_{\boldsymbol{T}}[-]$} & $\mathbf{1 0} \boldsymbol{K}_{\boldsymbol{Q}}[-]$ & $\boldsymbol{\eta}_{\mathbf{0}}[-]$ \\
\hline 4 & 0.1768 & 0.2996 & 0.660 \\
\hline $5(k-\varepsilon)$ & 0.1830 & 0.3120 & 0.653 \\
\hline $5($ Exp. $)$ & 0.1597 & 0.2837 & 0.651 \\
\hline 6 & 0.2022 & 0.3462 & 0.650 \\
\hline 7 & 0.2176 & 0.3772 & 0.643 \\
\hline
\end{tabular}

\subsection{Expanded Area ratio $A_{E} / A_{0}$ :}

In the second step, the number of blade is kept equal to five $(Z=5)$ with the pitch ratio $P / D=0.95$. While, the expanded area ratio is varied $\left(A_{E} / A_{0}\right)^{*}=0.3,0.5,0.8,1.0,1.2$ and 1.4. To calculate the new chord lengths; $C^{*}$, the equation below is used:

$$
C^{*}=\frac{\left(\frac{A_{g}}{A_{0}}\right)^{*}}{0.65} C
$$

The new projected propellers are illustrated in figure 11 with different expanded area ratio $A_{E} / A_{0}$. 
Belhenniche Samir. E, Aounallah Mohammed Imine Omar, Çelik Fahri
Effect of geometric configurations on hydrodynamic performance assessment of a marine propeller

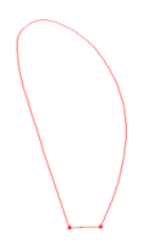

$\mathrm{A}_{\mathrm{E}} / \mathrm{A}_{0}=0.30$

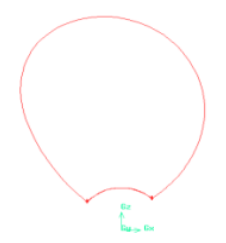

$\mathrm{A}_{\mathrm{E}} / \mathrm{A}_{0}=1.00$

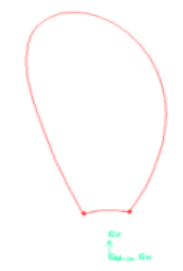

$\mathrm{A}_{\mathrm{E}} / \mathrm{A}_{0}=0.50$

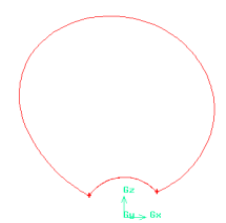

$\mathrm{A}_{\mathrm{E}} / \mathrm{A}_{0}=1.20$
$\mathrm{A}_{\mathrm{E}} / \mathrm{A}_{0}=0.80$
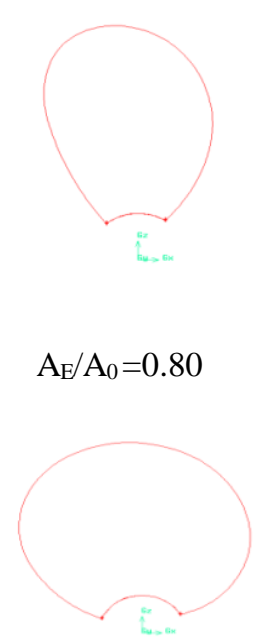

$\mathrm{A}_{\mathrm{E}} / \mathrm{A}_{0}=1.40$

Fig. 11 New blade shape for different expanded area ratio $A_{E} / A_{0}$

Figure 12 shows the shape of the new generated geometries. For the propellers with a higher expanded area $\left(A_{E} / A_{0}=1.0,1.2\right.$ and 1.4) and due to the overlapping of the adjacent blades, the computational domain is easily created from the flow passage and divided into 30 blocks [24].
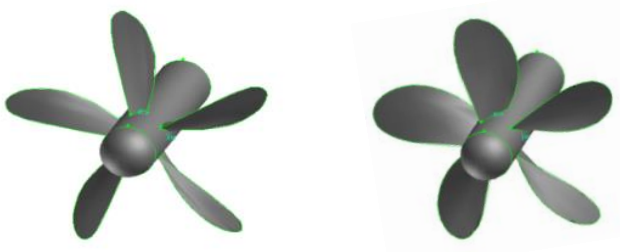

$$
\mathrm{A}_{\mathrm{E}} / \mathrm{A}_{0}=0.30
$$

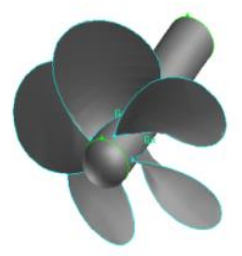

$\mathrm{A}_{\mathrm{E}} / \mathrm{A}_{0}=1.00$

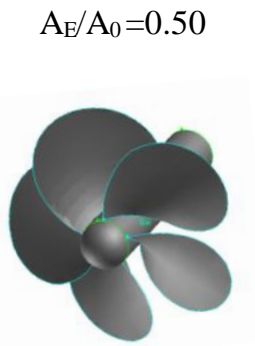

$\mathrm{A}_{\mathrm{E}} / \mathrm{A}_{0}=1.20$

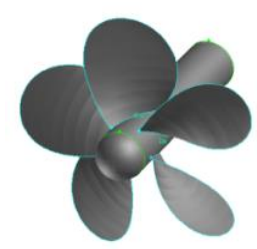

$\mathrm{A}_{\mathrm{E}} / \mathrm{A}_{0}=0.80$

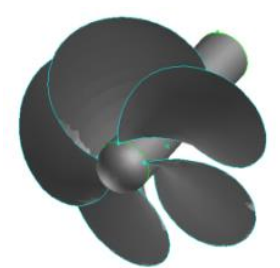

$\mathrm{A}_{\mathrm{E}} / \mathrm{A}_{0}=1.40$

Fig. 12 New Propeller geometries for different expanded area ratio

A hybrid mesh is adopted with tetrahedral cells inside the inner blocks and hexahedral cells for outer blocks. As the previous cases, the same cell size is kept for blade and shaft faces and also for overall volumes as it is illustrated in figure 13. 
Effect of geometric configurations on hydrodynamic performance assessment of a marine propeller

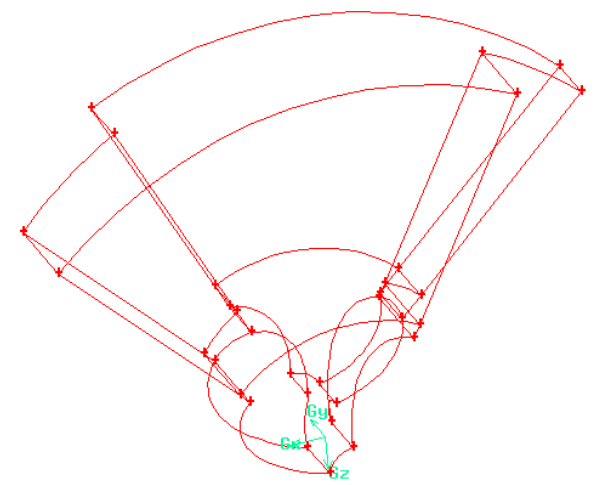

(a) Flow passage block

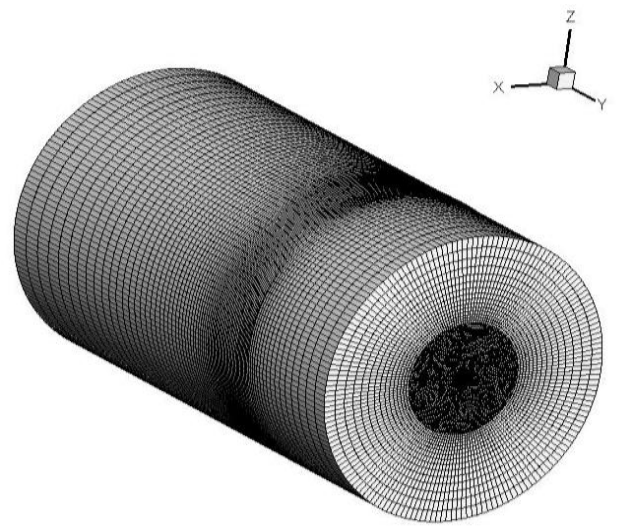

(c) The mesh of the full domain
Belhenniche Samir. E, Aounallah Mohammed Imine Omar, Çelik Fahri

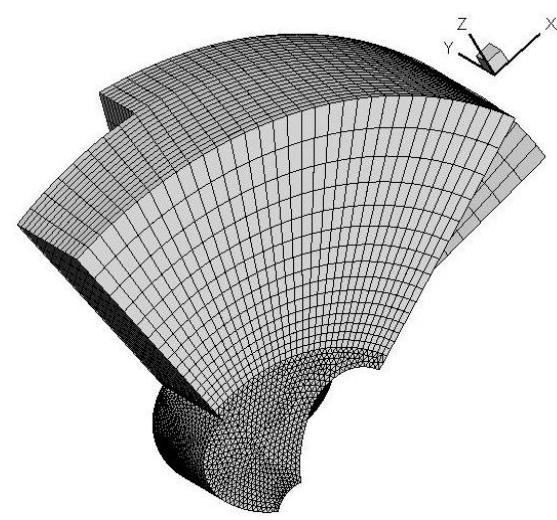

(b) The mesh of the inner and outer blocks

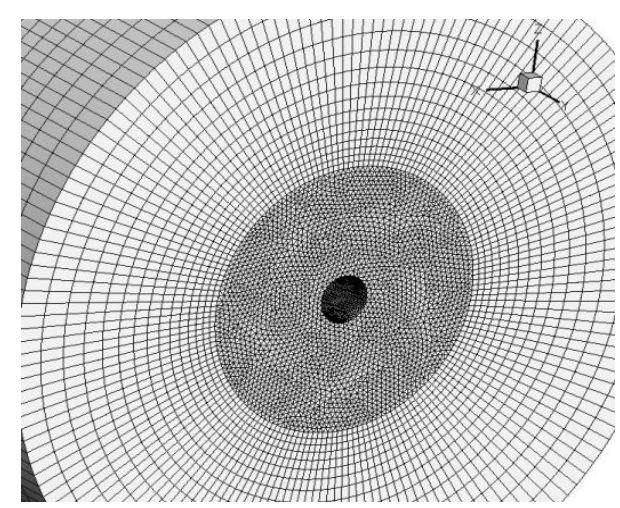

(d) The hybrid mesh at the inlet

Fig. 13 Computational domain and mesh generation

Figure 14 illustrates the open water characteristics for the propellers with different expanded area ratio compared with similar Wageningen propellers up to $A_{E} / A_{0}=1.05$. Graphs corresponding to $A_{E} / A_{0}=1.2$ and 1.4 are not presented here. The comparison shows good agreement of thrust, torque and efficiency for a wide range of advance coefficient.

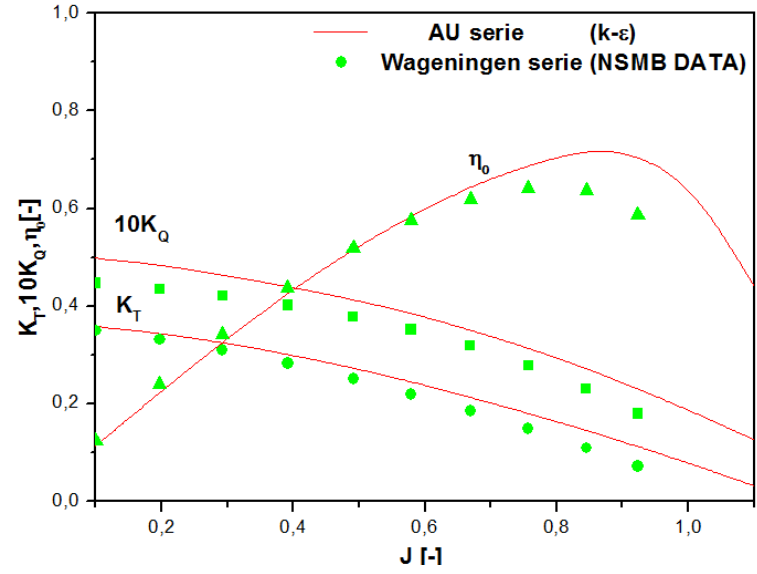

$\mathrm{A}_{\mathrm{E}} / \mathrm{A}_{0}=0.30$

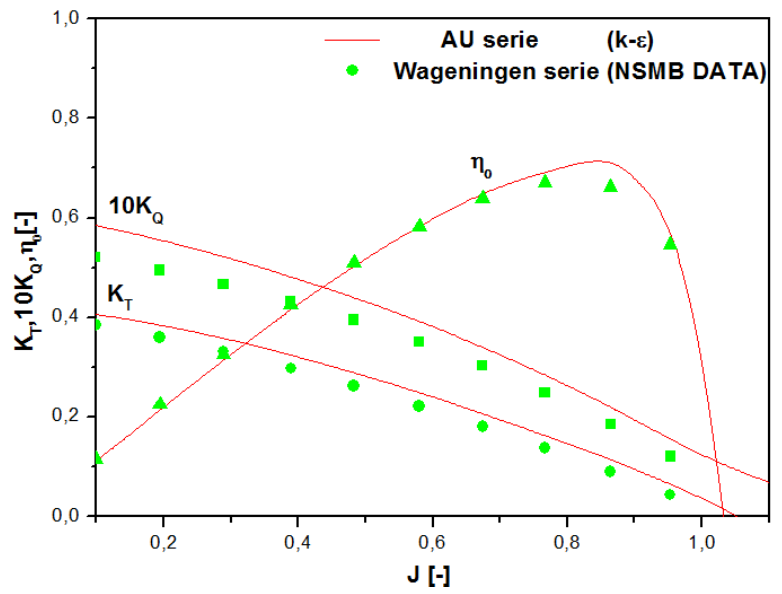

$\mathrm{A}_{\mathrm{E}} / \mathrm{A}_{0}=0.50$ 
Belhenniche Samir. E, Aounallah Mohammed Imine Omar, Çelik Fahri

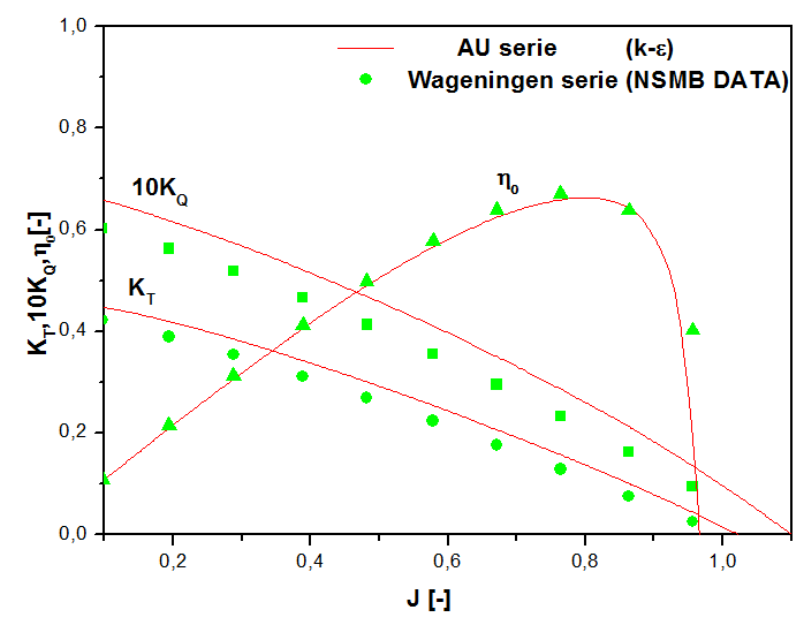

$\mathrm{A}_{\mathrm{E}} / \mathrm{A}_{0}=0.80$
Effect of geometric configurations on hydrodynamic performance assessment of a marine propeller

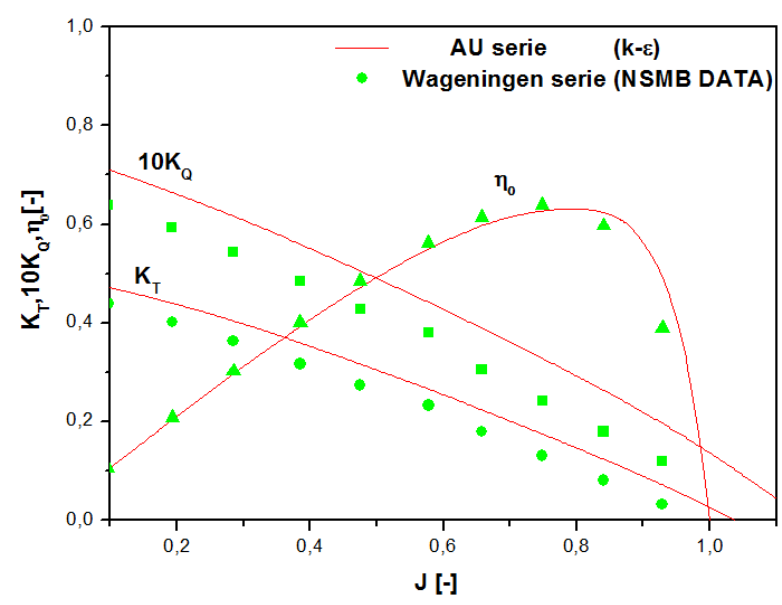

$\mathrm{A}_{\mathrm{E}} / \mathrm{A}_{0}=1.00$

Fig. 14 Open water characteristics for different $A_{E} / A_{0}$

Table 3 illustrates the effect of the expanded area ratio on the propeller open water characteristics for an advance coefficient of $J=0.7$. It is clearly seen that the efficiency of the propeller decreases generally with the increase of expanded area. For the cases $A_{E} / A_{0}=0.30$, 0.50 , the value of the efficiency is slightly superior added to the increase of the torque coefficient.

Table 3 Open water characteristics

\begin{tabular}{|c|c|c|c|}
\hline $\boldsymbol{A}_{\boldsymbol{E}} / \boldsymbol{A}_{\mathbf{0}}$ & $\boldsymbol{K}_{\boldsymbol{T}}[-]$ & $\mathbf{1 0}_{\boldsymbol{Q}}[-]$ & $\boldsymbol{\eta}_{\mathbf{0}}[-]$ \\
\hline 0.30 & 0.2015 & 0.3385 & 0.663 \\
\hline 0.50 & 0.1943 & 0.3250 & 0.666 \\
\hline $0.65(k-\varepsilon)$ & 0.1830 & 0.3120 & 0.653 \\
\hline $0.65($ Exp. $)$ & 0.1597 & 0.2837 & 0.651 \\
\hline 0.80 & 0.1910 & 0.3310 & 0.643 \\
\hline 1.00 & 0.2010 & 0.3610 & 0.620 \\
\hline 1.20 & 0.1722 & 0.3139 & 0.611 \\
\hline 1.40 & 0.1633 & 0.3123 & 0.583 \\
\hline
\end{tabular}

\subsection{The geometric pitch ratio $P / D$}

In the third step, the pitch ratio $P / D$ is varied and both blade number and expanded area are kept constant as the reference case, the geometric pitch angle $\varphi$ is calculated as follow:

$$
\varphi(i, j)=\operatorname{arctg} \frac{P(i)}{2 \pi r(j)}
$$

Where $i$ denote the variation of the pitch ratio and $j$ designate the cross section level.

Figure 15 shows the six new propeller geometries created by changing the geometric pitch ratio $P / D$. 
Effect of geometric configurations on hydrodynamic performance assessment of a marine propeller
Belhenniche Samir. E, Aounallah Mohammed Imine Omar, Çelik Fahri
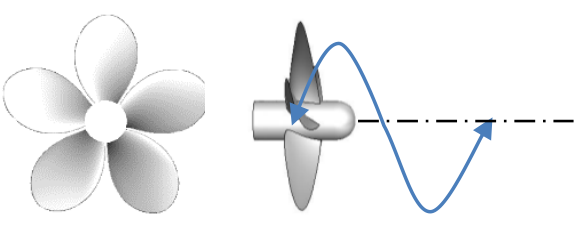

$\mathrm{P} / \mathrm{D}=0.89$
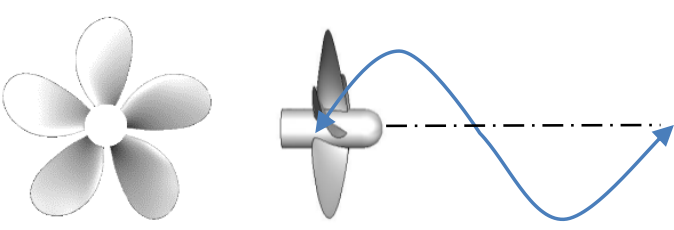

$\mathrm{P} / \mathrm{D}=1.17$
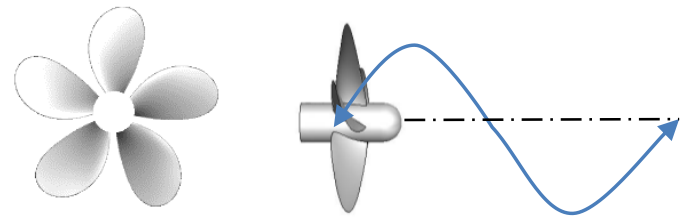

$\mathrm{P} / \mathrm{D}=1.01$
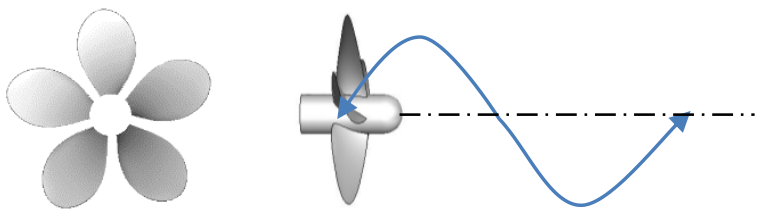

$\mathrm{P} / \mathrm{D}=1.28$
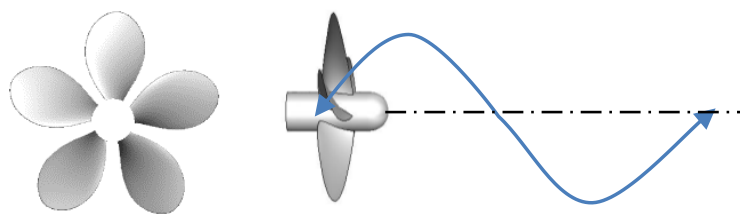

$\mathrm{P} / \mathrm{D}=1.39$

Fig. 15 Propeller geometries with different pitch ratio

Figure 16 shows the open water characteristics of different geometric pitch ratio propeller compared with similar Wageningen propellers for a wide range of advance coefficient. It is obviously seen that the numerical results obtained agree well with the experimental NSMB data.

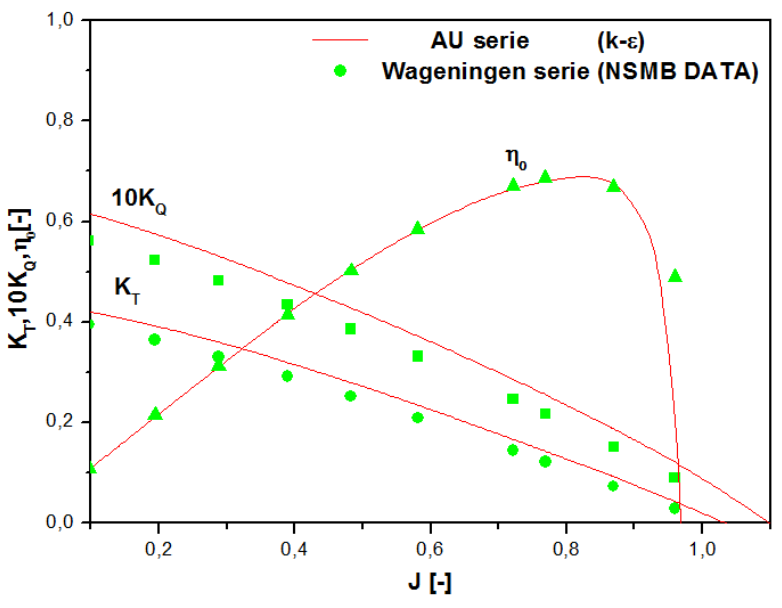

$\mathrm{P} / \mathrm{D}=0.89$

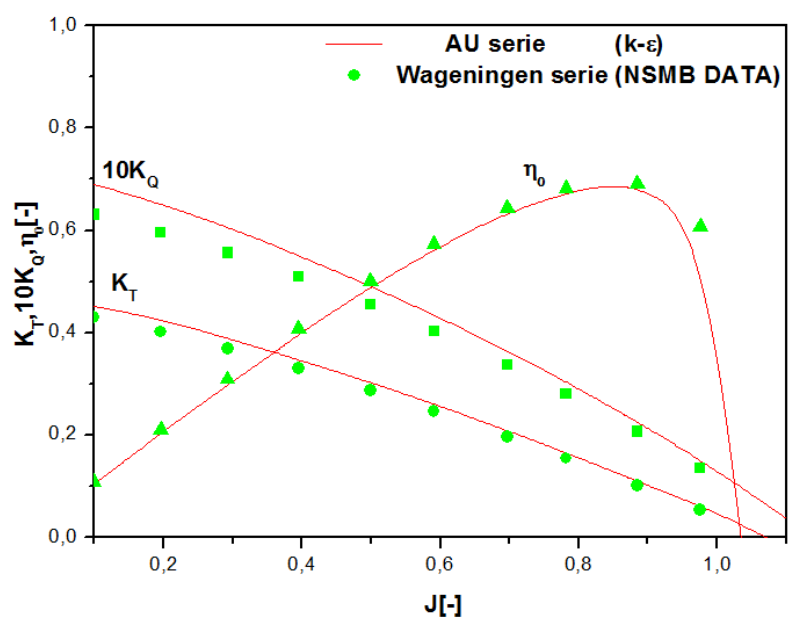

$\mathrm{P} / \mathrm{D}=1.01$ 
Belhenniche Samir. E, Aounallah Mohammed Imine Omar, Çelik Fahri
Effect of geometric configurations on hydrodynamic performance assessment of a marine propeller

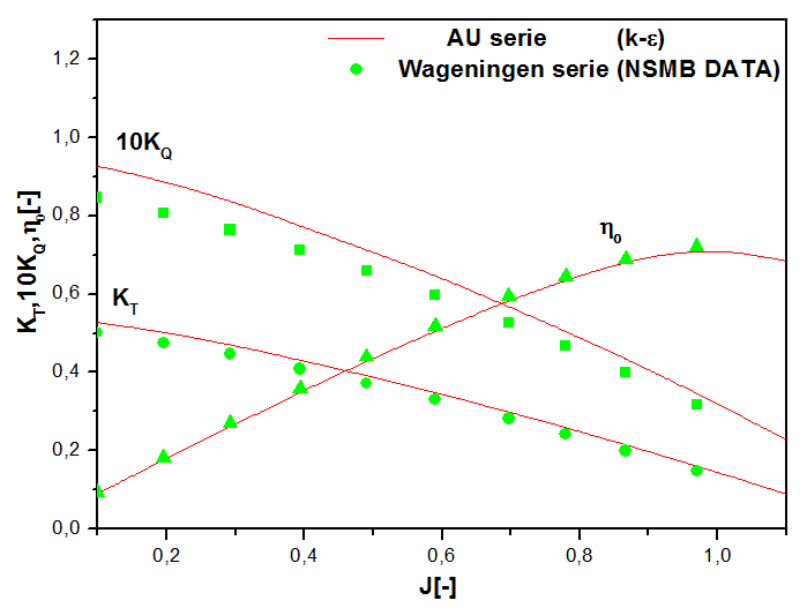

$\mathrm{P} / \mathrm{D}=1.17$

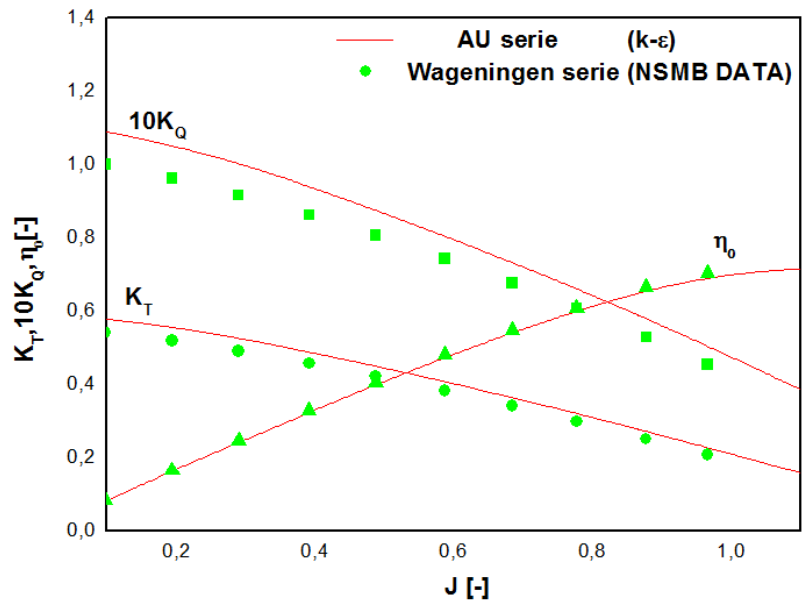

$\mathrm{P} / \mathrm{D}=1.28$

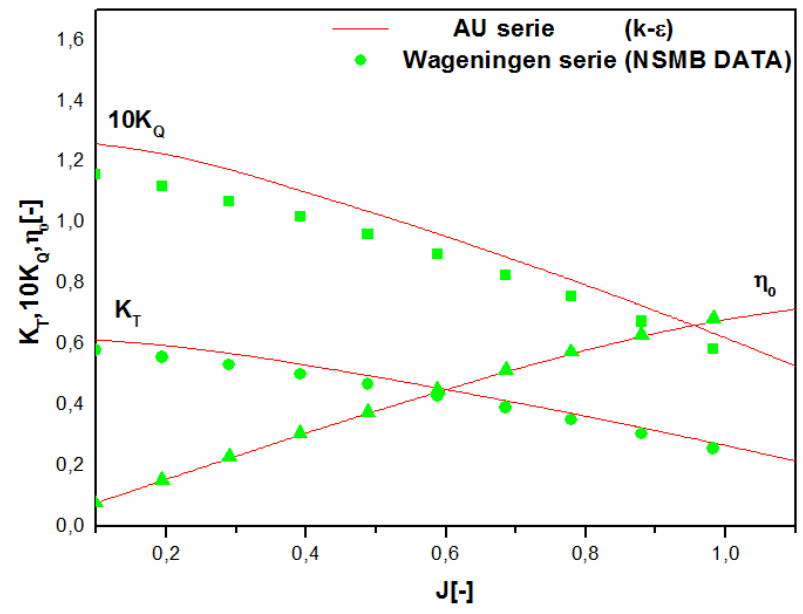

$\mathrm{P} / \mathrm{D}=1.39$

Fig. 16 Open water characteristics for different pitch ratio

Table 4 shows the comparison of the open water characteristics for different geometric pitch ratio for the fixed advance ratio $J=0.7$. In overall, the propeller efficiency decreases with the increase of the pitch ration expecting for the Seiun Maru. This latter remains the best comparing with other configurations.

Table 4 Open water characteristics

\begin{tabular}{|c|c|c|c|}
\hline \multicolumn{1}{|l|}{$\boldsymbol{P} / \boldsymbol{D}$} & $\boldsymbol{K}_{\boldsymbol{T}}[-]$ & $\mathbf{1 0}_{\boldsymbol{Q}}[-]$ & $\eta_{\mathbf{0}}[-]$ \\
\hline 0.89 & 0.1510 & 0.2630 & 0.639 \\
\hline $0.95(k-\varepsilon)$ & 0.1830 & 0.3120 & 0.653 \\
\hline $0.95($ Exp.) & 0.1597 & 0.2837 & 0.651 \\
\hline 1.01 & 0.2070 & 0.3620 & 0.637 \\
\hline 1.17 & 0.2973 & 0.5653 & 0.586 \\
\hline 1.28 & 0.3570 & 0.7210 & 0.552 \\
\hline 1.39 & 0.4080 & 0.8760 & 0.519 \\
\hline
\end{tabular}


Effect of geometric configurations on hydrodynamic performance assessment of a marine propeller
Belhenniche Samir. E, Aounallah Mohammed Imine Omar, Çelik Fahri

\section{Conclusion}

In the present study, the effect of the geometric characteristics on the propeller hydrodynamic performances is numerically studied. Based on the initial shape of the conventional Seiun Maru propeller, fourteen propeller configurations are created by changing number of blades, expanded area and geometric pitch ratios. The commercial code FLUENT is used to solve the averaged Navier-Stokes equations. The standard $k-\varepsilon$ and the $k-\omega S S T$ models are selected for the steady uniform and the transient non-uniform ship wake respectively. The computed hydrodynamic performances of the generated propellers are compared with similar Wageningen propeller series.

In overall, the numerical tests show satisfactory agreement with available data in the literature. The predictions of the RANS models in open water condition revealed that the standard $k-\varepsilon$ model returns superior results as well the commonly used $k-\omega S S T$. Both models can guarantee acceptable level of accuracy in uniform and non-uniform inflow cases and could be used as data for fatigue predictions. Regarding the good quantitative agreement of the standard $k-\varepsilon$ model compared to the $k-\omega S S T$, the first model is selected to conduct the parametric study.

Taking in account only the hydrodynamic considerations, the parametric study reveals that the efficiency of the four bladed propeller is superior compared with those for different blade number. The study concluded also that the propellers with lower expanded area ratio give best efficiency, however more torque should be provided. Concerning the pitch ratio effect, the same value as the conventional Seiun Maru propeller gives the best efficiency. As a conclusion the four bladed propeller with an expanded area of 0.65 and a pitch ratio of 0.95 is suggested for further experimental tests. Moreover, for vibration thoughts, the pair blades propeller are advised for their balance comparing to odd propellers. The reason is that two blades run through the dead zone at the same time, which balances each other and by consequent has less effect on shaft bending, contrary to the five blades propeller; where a single blade passes on time through the dead zone and by consequent create a power pulse, which bends highly the shaft.

\section{REFERENCES}

[1] T. Watanabe, T. Kawamura, Y. Takekoshi, M. Maeda, S. Rhee, 2003, Simulation of Steady and Unsteady Cavitation on a Marine Propeller Using A RANS CFD Code, Fifth International Symposium on Cavitation

[2] Bin Ji, X. Luo, Y. Wu, S. Liu, H. Xu, A. Oshima, 2010, Numerical investigation of unsteady cavitating turbulent flow around a full scale marine Propeller, Journal of Hydrodynamics, 22(5), pages 747-752. http://dx.doi.org/10.1016/S1001-6058(10)60025-X.

[3] T. Kanemaru, T. Ryu, A. Yoshitake, J. Ando, K. Nakatake 2013, The Modeling of Hub Vortex for Numerical Analysis of Marine Propeller Using a Simple Surface Panel Method "SQCM", Third International Symposium on Marine Propulsors smp'13, Launceston, Tasmania, Australia.

[4] Bin Ji, X. Luo, Y. Wu, 2013, Unsteady cavitation characteristics and alleviation of pressure fluctuations around marine propellers with different skew angles, Journal of Mechanical Science and Technology 28(4) pages 1339-1348. http://dx.doi.org/10.1007/s12206-013-1166-8.

[5] H. Ghassemi, 2009, The effect of Wake Flow and Skew Angle on the Ship Propeller Performance,

Transaction B: Mechanical Engineering Vol. 16, No. 2, pp. 149-158, Sharif University of Technology, Iran

[6] V. Krasilnikov, Jiaying Sun, Karl Henning Halse, 2009, CFD Investigation in Scale Effect on Propellers with Different Magnitude of Skew in Turbulent Flow, First International Symposium on Marine Propulsorssmp '09 , Trondheim, Norway 
Belhenniche Samir. E, Aounallah Mohammed Imine Omar, Çelik Fahri
Effect of geometric configurations on hydrodynamic performance assessment of a marine propeller

[7] M.A.Mossad, W.Yehia, 2011, Skewed Propeller Design for Minimum Induced Vibrations, $1^{\text {st }}$ international Symposium on Naval Architecture and Maritime, 24-25 October, Istanbul, Turkey.

[8] Hayati, 2012, A study on the effect of the rake angle on the performance of marine propellers, Mechanical Engineers, Part C: Journal of Mechanical Engineering Science April 2012 vol.226 no. 4 940955

[9] M. Ghassabzadeh, Hassan Ghassemi, Maryam Gh. Saryazdi, 2013, Determination of Hydrodynamics Characteristics of Marine Propeller Using Hydro-elastic Analysis, Brodogradnja, Journal of Naval Architecture and Shipbuilding Industry, Volume 64, No: 1, pages: 40-45.

[10] I. Yasuhiko, 2013, A Development of a Propeller with Backward Tip Raked Fin, Third International Symposium on Marine Propulsion smp'13, Tasmania, Australia.

[11] P. Spalart and S. Allmaras, A one-equation turbulence model for aerodynamic flows, Technical Report AIAA-92-0439, American Institute of Aeronautics and Astronautics, 1992.

[12] Launder, B. E.; Spalding, D. B. 1972, Lectures in Mathematical Models of Turbulence, Academic Press, London, England.

[13] Wilcox, D. C. 1998. Turbulence Modeling for CFD, DCW Industries, Inc., La Canada, California,

[14] F. R. Menter, Two-equation eddy-viscosity turbulence models for engineering applications, AIAA J. 32 (8) pp.1598-1605, 1994.

Chao Wang, S. Huang, X. Chang, M. He, 2010, Applying periodic boundary conditions to predict open water propeller performance, Journal of Marine Science and applications, (9) 262-267.

[16] S.E. Belhenniche, M. Aounallah, O. Imine, F. Çelik 2012, Application of CFD in Analysis of Steady and Unsteady Turbulent Flow Past a Marine Propeller, International Conference of Heat and Mass Transfer ICHMT Palermo (Italy). http://dx.doi.org/10.1615/ichmt.2012.procsevintsympturbheattransfpal.500.

[17] Ekinci, S. Çelik, F. and Güner M. " A Practical Noise Prediction Method for Cavitating Marine Propellers ", Brodogradnja, Journal of Naval Architecture and Shipbuilding Industry, Volume 61, No:4, pages: 359-366, (2010).

[18] Ukon, Y., Kurobe, Y.and Kudo, T., 1989, Measurement of pressure distribution on a conventional and highly skewed propeller model - under non cavitating condition- (in Japanese), Journal of the society of naval architects of Japan, Vol.165, 1989, pp.83-94.

[19] Ukon, Y., Kurobe, Y.and Kudo, H. Kamiriisa, H. Yuasa, H. Kubo, Y. Itadani, 1990 Measurement of Pressure distribution on a full scale propeller -measurement on a conventional propeller- (in Japanese),Journal of the society of naval architects of Japan,Vol.168, 1990 pp.65-75.

[20] Koyama, K., 1972, A Numerical Analysis for the Lifting Surface, Theory of a Marine Propeller (in Japanese)", Journal of the Society of Naval Architects of Japan, Vol. 132, pp. 91-98. http://dx.doi.org/10.2534/jjasnaoe1968.1972.132_91

[21] Arikan, Y., Dogrul, A., Celik, F., "Performance Analysis and Investigation of The Slipstream Flow of Podded Propellers", Brodogradnja, Journal of Naval Architecture and Shipbuilding Industry, Volume 63, No: 3, pages: 226-233, (2012).

[22] K. Nakatake, J. Ando, K. Kataoka and A. Yoshitake, 2002, A simple surface panel method SQCM for ship hydrodynamics, IABM, International association for boundary element methods, UT Austin, TX, USA.

[23] A. F. Molland, 2011, Ship Resistance and Propulsion, Practical Estimation of Ship Propulsive Power, first edition.

[24] T. Sipilä1, T. Siikonen, I. Saisto, 2011, FINFLORANS-Predictions for Propeller Performance, Second International Symposium on Marine Propulsors smp'11, Hamburg, Germany. http://dx.doi.org/10.1017/CBO9780511974113.

Submitted: 28.09.2015. Belhenniche Samir. E samir.belhenniche@univ-usto.dz

Aounallah Mohammed

Accepted: 01.08.2016 Department of Marine Engineering, Naval Aero-Hydrodynamic Laboratory USTO

MB, Oran 31000, Algeria

Imine Omar

Department of Marine Engineering, Aeronautics and Propulsive Systems Laboratory USTO MB, Oran 31000, Algeria

Çelik Fahri

Yildiz Technical University, Faculty of Naval Architecture and Maritime 